\title{
Direct determination of small RNAs using a biotinylated polythiophene impedimetric
}

genosensor

Diego Voccia ${ }^{1}$, Marta Sosnowska ${ }^{2}$, Francesca Bettazzi $^{1}$, Giuseppina Roscigno ${ }^{3,4}$, Emiliano Fratini ${ }^{1}$, Vittorio De Franciscis ${ }^{3}$, Gerolama Condorelli ${ }^{3,4}$, Raghu Chitta ${ }^{5}$, Francis D'Souza ${ }^{6}$, Wlodzimierz Kutner, ${ }^{2,7}$, and Ilaria Palchetti ${ }^{1}{ }^{*}$

${ }^{1}$ Dipartimento di Chimica, Università degli Studi di Firenze, Via della Lastruccia 3, 50019, Sesto Fiorentino, Italy

${ }^{2}$ Department of Physical Chemistry of Supramolecular Complexes, Institute of Physical Chemistry, Polish Academy of Sciences, Kasprzaka 44/52, 01-224, Warsaw, Poland ${ }^{3}$ Istituto di Endocrinologia e Oncologia Sperimentale, CNR, 80138, Napoli, Italy

${ }^{4}$ Dipartimento di Medicina Molecolare e Biotecnologie Mediche, Università degli Studi di Napoli Federico II, Napoli, Italy

${ }^{5}$ Chemistry Department, Central University of Rajasthan, Kishangarh, Rajasthan, India ${ }^{6}$ Department of Chemistry, University of North Texas, 1155, Union Circle, 305070, Denton, TX, United States

${ }^{7}$ Faculty of Mathematics and Natural Sciences, School of Sciences, Cardinal Stefan Wyszynski University in Warsaw, Wóycickiego 1/3, 01-815 Warsaw, Poland

* Corresponding author: Ilaria Palchetti, phone: +390554573323, e-mail address: ilaria.palchetti@unifi.it 


\begin{abstract}
Herein, direct determination of small RNAs is described using a functional-polymer modified genosensor. The analytical strategy adopted involves deposition by electropolymerization of biotinylated polythiophene films on the surface of miniaturized, disposable, gold screen-printed electrodes, followed by the layer-by-layer deposition of streptavidin, and then biotynilated capture probes. A small RNA (miR-221) target was determined via the impedimetric measurement of the hybridization event in a label-free and PCR-free approach. Under optimized conditions, the limit of detection (LOD) was 0.7 pM miR-221 (15\% RSD). The genosensor was applied for determination of miR-221 in total RNA extracted from human lung and breast cancer cell lines, discriminating between the cancer-positive and -negative cells, without any amplification step, in less than $2 \mathrm{~h}$.
\end{abstract}

Keywords: small RNA, microRNA, genosensor, bis(2,2'-bithien-5-yl)methane, electrochemical impedance spectroscopy 


\section{Introduction}

Recent discovery and characterization of small non-protein-coding regulatory RNAs, such as short interfering RNAs (siRNAs), microRNAs (miRNAs, miRs), PIWI-associated RNAs (piRNAs) and other families of short RNAs (Campuzano et al., 2016) has led to a rapid expansion of research directed at elucidating their regulatory function and expression pattern. Being involved in RNA interference (RNAi), a biological process in which small RNAs modulate gene expression, typically by destructing specific messenger RNA (mRNA) molecules, small RNAs have been correlated to many diseases, and, as a result, they have been proposed as diagnostic and prognostic clinical biomarker candidates (Cortez et al., 2011).

Currently, Northern blotting, microarrays, quantitative Real-Time PCR (qRT-PCR), and nextgeneration sequencing are techniques predominantly used for determination of small RNAs (Graybill and Bailey, 2016). However, most of these techniques are incompatible with the point-ofcare testing (POCT). Moreover, all PCR-based detection schemes are complicated by the short size of the small RNAs, due to similarities between the length of the target and the primers. Therefore, development of new, compact, and easy to use rapid analytical tools for small RNAs decentralized analysis of appropriate sensitivity and multiplexing capability, without using PCR, is becoming more and more important. These considerations portend a role for emerging biosensing technologies and in this view, electrochemical genosensors have been proposed as interesting options for small RNAs determination in terms of the assay time, simplicity in use, and small amount of sample required (Palchetti, 2014), (Labib and Berezovski, 2015), (Campuzano et al., 2014), (Erdem and Congur, 2014), (Kilic et al., 2016), (Teo et al., 2014), (Tran et al., 2014b).

Herein, we report on devising and fabricating a label-free impedimetric genosensor for small RNA determination using a miniaturized, polymer-modified electrochemical platform. Conducting polymers offer a powerful opportunity for biosensor development (Cosnier and Holzinger, 2011). They provide easy routes to afford sensing selectivity, resistance to fouling, analyte preconcentration, and improvement of electrochemical properties, especially when functional moieties are introduced to the polymer backbone (Huynh et al., 2015).

Some approaches based on the use of conducting polymers for miRNAs determination have already been reported. For that purpose, a polymer-based genosensor, made of charge-neutral morpholino capture probes (CPs) immobilized on indium-tin oxide (ITO)-coated glass slides, was used (Gao et al., 2013). Upon hybridization, the neutral surface of the genosensor was converted to an anionic form by the hybridized miRNA strands. An insulating polymer film, poly(3,3'dimethoxybenzidine) (PDB), was then deposited by catalytic action of the horseradish peroxidase enzyme in the presence of $\mathrm{H}_{2} \mathrm{O}_{2}$, leading to a limit of detection (LOD) of $2 \mathrm{fM}$. Then, a label-free 
and reagent-less miRNA genosensor, based on an interpenetrated network of carbon nanotubes and an electroactive polymer was devised (Tran et al., 2013). The nanostructured polymer film revealed a defined electroactivity in a neutral aqueous solution arising from the quinone group embedded in the polymer backbone. When the miR-141 target was added, the current signal increased because of the increase of the polymer electroactivity. A LOD of $\sim 8 \mathrm{fM}$ was reported. Recently, CPs of chargeneutral peptide nucleic acid (PNA) and guided deposition of polyaniline (PAn) were used for labelfree impedimetric genosensing (Deng et al., 2014). In particular, a conventional gold electrode, coated with the PNA CPs was first hybridized to a target miRNA. After rinsing, the hybridized electrode was immersed in $0.10 \mathrm{M}$ potassium phosphate buffer $(\mathrm{pH}=3.0)$ containing aniline, $\mathrm{H}_{2} \mathrm{O}_{2}$, and a G-quadruplex-hemin DNAzyme. The DNAzyme catalyzed polymerization of aniline, and then the hybridized miRNA strands guided the deposition of PAn, thus resulting in formation of a thin PAn film on the genosensor surface. The electron-transfer impeding power of the PAn film in an alkaline solution was used to determine concentration of the target miRNA. A LOD of $0.50 \mathrm{fM}$ was successfully reported.

Recently, a functional monomer of bis(2,2'-bithien-5-yl)methane derivatized with biotin, was reported by us (Sosnowska et al., 2013). The presence of the bis(2,2'-bithien-5-yl)methane moiety in the monomer allowed for straightforward oxidative electrochemical polymerization resulting in deposition of a polymer bearing an intact biotin moiety, available for streptavidin binding. This strategy provided us the ability to nanostructure the genosensor surface, since up to three biotinmodified CPs can be immobilized on each streptavidin nanospot. Nanostructuration increases the CP immobilization efficiency in terms of orientation, loading, and steric hindrance. This polymer was characterized using piezoelectric microgravimetry (PM) at a quartz crystal microbalance (QCM) and electrochemical impedance spectroscopy (EIS) measurements for the determination of model DNA, achieving the LOD of $50 \mathrm{nM}$ and $0.5 \mathrm{pM}$, for the PM and EIS transduction, respectively (Sosnowska et al., 2013).

Starting from this study, in the present work we explored the possibility to use this polymer for label-free impedimetric determination of small RNAs. The earlier EIS approach (Sosnowska et al., 2013) was developed using a conventional bulk glassy carbon electrode and tested with synthetic DNA oligonucleotides. In the present work, we described an easy-to-perform and rapid approach to label-free and PCR-free determination of miRNAs based on compact, disposable, planar miniaturized plastic electrochemical cells in line with the POCT concept. The procedure of electropolymerization was modified in order to use an aqueous rather than organic solvent solution. Finally, the assay was successfully applied for determining miR-221 in total RNA (RNA tot) 
extracted from human lung and breast cancer cell lines. Discrimination between the cancer-positive and -negative cells, without any amplification step, in less than $2 \mathrm{~h}$ was accomplished.

\section{Experimental}

\subsection{Materials}

Streptavidin from Streptomyces avidinii, biotin, diethyl pyrocarbonate (DEPC) and ethanol (96\%) were from Sigma-Aldrich. Disodium hydrogen phosphate, sodium dihydrogen phosphate, potassium hexacyanoferrate(II and III), sodium chloride, tetra-n-butylammonium bromide [(TBA)Br] and acetonitrile were from Merck. Bis(2,2'-bithien-5-yl)-(4-hydroxyphenyl)methane biotin ester was synthesized according to the literature (Sosnowska et al., 2013). For this, first bis(2,2'-bithien-5-yl)-(4-hydroxyphenyl)methane was prepared using the procedure reported in (Pietrzyk et al., 2009). Then, the product was used for esterification with biotin in the presence of EDCI as a carboxyl activating agent, as reported in (Sosnowska et al., 2013). MilliQ water of 18 $\mathrm{M} \Omega \mathrm{cm}$ (DEPC treated) was used for the preparation of solutions. All the reagents were of analytical grade.

Synthetic oligonucleotides, all from MWG Biotech AG, were, as follows.

CP: 5' GAA-ACC-CAG-CAG-ACA-ATG-TAG-CT - biotin TEG 3'

miR-221: 5' AGC-UAC-AUU-GUC-UGC-UGG-GUU-UC 3'

miR-222: 5' AGC-UAC-AUC-UGG-CUA-CUG-GGU-CUC 3'

miR-16: 5' UAG-CAG-CAC-GUA-AAU-A 3'

miR-21: 5' AGC TTA TCA GAC TGA TGT TGA 3'

\subsection{Cell lines, cell transfection and total RNA extraction}

The human non-small-cell lung cancer Calu1 cell line was grown in Dulbecco's modified Eagle medium (DMEM). The human non-small-cell lung cancer H460 cell line was grown in Roswell Park Memorial Institute medium (RPMI). Both media were supplemented with 10\% heatinactivated fetal bovine serum (FBS) with $2 \mathrm{mM} \mathrm{L-glutamine}$ and $100 \mathrm{U} / \mathrm{mL}$ penicillinstreptomycin. The T47D cell line (HTB-133) was acquired from American Type Culture Collection (ATCC) and maintained in RPMI with GlutaMAX, supplemented with bovine insulin $(10 \mathrm{mg} / \mathrm{mL}$, Sigma, St. Louis, MO, USA).

For transient transfection with miRs, cells at 50\% confluence were transfected using Oligofectamine (Life Technologies, Milan, Italy) with $100 \mathrm{nM}$ of pre-miR-221, scrambled (Scr), anti-scrambled (antiScr) or anti miR-221 sequences (Ambion, Life Technologies, Milan, Italy). 
$\mathrm{RNA}_{\text {tot }}$ was extracted with the Trizol reagent in accordance with manufacturer's instructions (Invitrogen) (Garofalo et al., 2008). The $\mathrm{RNA}_{\text {tot }}$ concentration was determined with NanoDrop (Thermo Scientific). Before electrochemical determinations, $\mathrm{RNA}_{\text {tot }}$ extracts were diluted with phosphate buffer (PB), $\mathrm{pH}=7.0$, to the desired concentration. In particular, $\mathrm{RNA}_{\text {tot }}$ was diluted to 10 $\mathrm{ng} / \mu \mathrm{L}$ in the case of both T47D-miR221 transfected cell samples and scrambled transfected cell samples, and to $300 \mathrm{ng} / \mu \mathrm{L}$ in case of T47D-antimiR transfected samples and anti-scrambled transfected samples. The RNA tot was diluted to $100 \mathrm{ng} / \mu \mathrm{L}$ in the case of $\mathrm{H} 460$ and Calu1 cell lines.

For clarity, samples of T47D-antiScr and T47D-Scr were used as models of the basal expression level of miR-221 in the T47D cell lines. They represent two populations of the same cell lines genetically modified with two different sequences, namely, antiScr and Scr, respectively.

The Scr and antiScr oligonucleotides have the same nucleotide length but match neither pre-miR221 nor the anti-sense oligonucleotide (anti-miR). For T47D-miR-221 samples, the cells were genetically forced to overexpress miR-221, whereas the cells were genetically forced to downexpress miR-221 in the case of T47D-antimiR samples.

\subsection{Electrochemical instrumentation and procedures}

Electrochemical measurements were performed with a three-electrode cell using an Autolab PGSTAT10 electrochemistry system equipped with the FRA2 module (EcoChemie). The planar, screen-printed electrochemical cell consisted of a carbon auxiliary electrode, an Ag pseudoreference electrode, and a 3-mm diameter gold disk working electrode (WE) (Baydemir et al., 2016) (Voccia et al., 2015). Each potential is referred to the pseudo-reference electrode. All measurements were performed at room temperature. The screen-printed electrochemical cells were used as disposable sensors.

Before electropolymerization, the WE was pretreated with multiple-pulsed amperometry in a stirred $0.5 \mathrm{M} \mathrm{H}_{2} \mathrm{SO}_{4}, 10 \mathrm{mM} \mathrm{KCl}$ solution. The triple-potential pulse sequence of $-0.3 \mathrm{~V}$ for $0.30 \mathrm{~s}$, $0.0 \mathrm{~V}$ for $0.30 \mathrm{~s}$ and $+1.0 \mathrm{~V}$ for $0.15 \mathrm{~s}$ (150 cycles) was applied (Lucarelli et al., 2005). The bis(2,2'bithien-5-yl)-(4-hydroxyphenyl)methane biotin ester polymer was deposited on the WE surface by electropolymerization under potentiodynamic conditions by exposing the planar electrochemical cell to a $60 \mu \mathrm{L}$ sample of the monomer solution $(0.1 \mathrm{mM}$ monomer in $10 \mathrm{mM}$ (TBA)Br in a mixed solvent solution of ethanol : acetonitrile : water, $1: 1: 10, v / v / v)$ and by linear cycling the potential in the range of +0.50 to $+1.30 \mathrm{~V}$, with a scan rate of $50 \mathrm{mV} / \mathrm{s}$.

Then, the polymer coated WE surface was exposed to a $10-\mu \mathrm{L}$ sample of a $0.2 \mathrm{mg} / \mathrm{L}$ streptavidin solution in $0.5 \mathrm{M} \mathrm{PB}(\mathrm{pH}=7.0)$ for $20 \mathrm{~min}$. Before immobilization of the biotinylated DNA CP, the modified sensors were twice rinsed with a $30 \mu \mathrm{L}$ sample of PB. The sensors were 
then exposed to the $\mathrm{CP}$ solution $(10 \mu \mathrm{L}, 4 \mu \mathrm{M} \mathrm{CP}$ in $\mathrm{PB}, \mathrm{pH}=7.0)$ for $20 \mathrm{~min}$. Both the streptavidin modification and CP immobilization steps were allowed to proceed with the sensor stored in a Petri dish to protect the solutions from evaporation. The bottom of a large $(8.5-\mathrm{cm}$ diameter $)$ closed Petri dish was covered with a plastic dish ( $7 \mathrm{~cm}$ diameter); the chips were set down on the upper side of the plastic dish, whereas under the other side there was a water-soaked paper pad to maintain high humidity. The Petri dish was wrapped with Parafilm and kept at room temperature. Both the streptavidin and CP solutions were manually dropwise dispensed on the WE surface.

Hybridization experiments were carried out using target sequences in a direct format, by exposing the $\mathrm{CP}-$ modified $\mathrm{WE}$ to a $10-\mu \mathrm{L}$ drop of the target sequence solution in $\mathrm{PB}, \mathrm{pH}=7.0$, for $20 \mathrm{~min}$. A non-complementary sequence was used as the negative control of the hybridization event. After hybridization, the sensors were rinsed twice with a $30-\mu \mathrm{L}$ aliquot of $\mathrm{PB}$.

The cell samples were analyzed by exposing the $\mathrm{CP}$-modified WE to a $10-\mu \mathrm{L}$ drop of the diluted $\mathrm{RNA}_{\text {tot }}$ extract for $20 \mathrm{~min}$.

The EIS measurements were performed with a sinusoidal voltage of $10 \mathrm{mV}$ amplitude, an open circuit potential value of $\sim 0.13$ (vs Ag pseudo-reference electrode) in a frequency range of 50 $\mathrm{kHz}$ to $10 \mathrm{mHz}$. A $1 \mathrm{mM} \mathrm{Fe}(\mathrm{CN})_{6}^{3-/ 4-}$ (equimolar) in $0.1 \mathrm{M}$ phosphate buffer saline (PBS), $\mathrm{pH}=7.4$, was used as the redox probe. The EIS spectra were plotted as the complex plane diagrams (Nyquist plots). The Randles-Ershler equivalent circuit parameters were successfully applied to fit the acquired data. In this circuit, $R_{\text {et }}$ describes the electron transfer resistance between the electrode and the redox species in solution. Therefore, $R_{\mathrm{et}}$ corresponds to the resistance of the electrode, on which a faradaic reaction proceeds. The value of this resistance is affected by any surface change. The $R_{\mathrm{S}}$ element represents the solution resistance; herein, its value is constant. For electrodes coated with the polymer films, the double-layer capacity normally used in the Randles circuit was herein replaced by the constant phase element $\left(Q_{\mathrm{dl}}\right)$ to take into account the roughness of the modified sensor surfaces. The Warburg impedance $\left(Z_{\mathrm{W}}\right)$ is usually recorded at low frequency. It corresponds to mass transfer to the electrode accompanying the redox process.

In order to compare results obtained from different electrodes, the ratio of the electron-transfer resistances $R_{\text {et }}$ ( $\Delta R$ ratio) was used. The $\Delta R$ ratio was determined as the ratio of $\left(R-R_{\text {bare }}\right)$ to $R_{\text {bare, }}$ where $R$ and $\mathrm{R}_{\text {bare }}$ represent the $R_{\text {et }}$ after and before polymer electrodeposition (or after polymer electrodeposition, streptavidin association and CP immobilization), respectively. In order to quantify the miRNA target, the $\Delta R$ ratio was determined as the ratio between $\left(R-R_{0}\right)=\Delta R_{\text {et }}$ and $R_{0}$, where $R$ is the $R_{\text {et }}$ recorded after target binding, and $R_{0}$ is the $R_{\text {et }}$ recorded after incubation in the same condition but with zero target concentration. 


\subsection{FE-SEM and FTIR characterization}

Scanning electron microscopy (SEM) was performed on uncoated samples using a field emission (FE) scanning microscope IIGMA (Carl Zeiss Microscopy GmbH, Germany). High-resolution images were acquired with an acceleration voltage of $1.5 \mathrm{kV}$ and a working distance of $\sim 3 \mathrm{~mm}$ using the In-lens high resolution secondary electron detector. Because of a low acceleration voltage, no surface metallization was applied to any sample.

Infrared spectroscopy measurements were performed at room temperature with a Nexus 870 FT-IR spectrometer from Thermo Nicolet. Data were collected in attenuated total reflectance (ATR) mode. The spectra were acquired by gathering 128 scans to get an acceptable signal-to-noise ratio. Optical resolution was $8 \mathrm{~cm}^{-1}$ and the spectral range was 400 to $4000 \mathrm{~cm}^{-1}$.

Before performing the SEM and FTIR measurements, samples were thoroughly rinsed with Milli-Q water, and then dried under reduced pressure in a gas-tight desiccator by using a membrane pump for a few hours.

\section{Results and discussion}

Scheme 1 illustrates five consecutive steps of the developed genosensor preparation procedure. The first step involved deposition of the biotinylated polymer film by electropolymerization (i). Then, this film was decorated with streptavidin (ii). The assembled streptavidin molecules offered a useful platform for immobilization of biotinylated CPs on the sensor surface (iii). The CP-modified sensor was then allowed to react with the analyte (the target miRNA) (iv). The resulting hybridization was monitored with EIS in the presence of the $\mathrm{Fe}(\mathrm{CN})_{6}^{3-/ 4-}$ redox probe (v). Electrostatic repulsion between the negatively charged ions of the redox probe and the miRNA polyanionic backbone was expected to account for an increase of the electron transfer resistance $\left(R_{\mathrm{et}}\right)$ between the WE surface and the redox probe in solution. In the following sections, electrochemical characterization and morphological evaluation of the genosensor as well as its analytical performance are discussed. Different parameters that can influence the assay were optimized and results summarized in Table S1.

\subsection{Modification and characterization of the sensor surface}

The polymer film was deposited by electropolymerization from an aqueous solution of the monomer and not from a typically used anhydrous organic solvent solution (Sosnowska et al., 2013), because the electrodes used were not compatible with organic solvents. That is because, ink formulations employed for screen-printing were based on a thermoplastic resin binder and the 
electrodes were printed onto a polyester substrate. The polymer was deposited on the WE surface by linear cycling of potential in the range of +0.5 to $+1.3 \mathrm{~V}$. In the current-potential curves (Figure 1 , solid line), an anodic peak current was observed at around $+1.1 \mathrm{~V}$. This peak corresponds to the oxidation of the bisthiophene moiety of the functional monomer, leading to the formation of the polymer film. Interestingly, there was a crossover of curves recorded in the forward and reverse scans at $\sim 0.9 \mathrm{~V}$. This crossover appearing in all current-potential curves of the first electropolymerization cycle was historically interpreted as initiation of nucleation of the corresponding polymer and called a "nucleation loop" (Heinze et al., 2007), (Kakhki et al., 2012). Recently, this "loop behavior" was also explained in terms of a homogeneous reaction between the oligomeric species and the monomer (in an autocatalytic mechanism), which facilitated initiation of oxidation of the monomer (Heinze et al., 2007). This effect was extensively studied for thiophene and substituted thiophene polymers (Heinze et al., 2007).

Importantly, the anodic peak of electropolymerization still appeared despite the presence of water, a known electropolymerization inhibitor. However, the current of this peak decreased in consecutive potential cycles (data not shown). This behavior can be explained considering that electrical resistivity of a conducting polymer film increases in the course of potential cycling in an aqueous buffer solution (Spires et al., 2011). Moreover, an anodic peak decrease in consecutive cycles has already been reported for electropolymerization as well, even in an organic solvent solution, of other monomers of bis(2,2'-bithien-5-yl)methane, and attributed to the increase of the $R_{\text {et }}$, because of the growth of a polymer film much less conductive than the bare electrode (Huynh et al., 2013a), (Huynh et al., 2013b).

The dash curve in Figure 1 corresponds to the cyclic voltammogram of supporting electrolyte solution for the gold WE.

Deposition of a polymer film of high $R_{\text {et }}$ means that the electron transfer between the electrode substrate and the redox probe in solution can be significantly hindered as a result of high film resistivity. In the proposed assay (Scheme 1), a polymer film with higher $R_{\text {et }}$ (background signal) can influence the analytical performance of the genosensor. This is because the $R_{\text {et }}$ change, as result of target hybridization (analytical signal), could be more indiscernible. Therefore, the extent of the electroactivity of the polymer film, governed by the number of potential cycles, was thoroughly evaluated by EIS measurements in the presence of the $\mathrm{Fe}(\mathrm{CN})_{6}{ }^{3-/ 4-}$ redox probe. The EIS experiments were performed before and after the CP immobilization and target hybridization.

As shown in Figure $\mathrm{S} 1$, a slight $R_{\text {et }}$ increase with the scan number increase for the polymer film coated sensors, indicated that the background signal was not much influenced by potential cycling. On the contrary, the $R_{\text {et }}$ increased after CP immobilization. This increase might be ascribed to the 
intrinsic negative charge of the DNA-CP. Moreover, the $R_{\text {et }}$ of the CP modified sensors increased with the number of potential cycles reaching a constant value after 30 cycles. Apparently, the higher the number of cycles, the higher amount of the negatively charged DNA-CP is immobilized on the surface. Hence, the optimum number of cycles was 30 for efficient CP immobilization.

Then, the hybridization extent, in terms of $R_{\text {et }}$ values, was evaluated. In Figure 2, there are faradaic impedance spectra for the bare WE, for the layer-by-layer deposited assemblies and for determination of $1 \mathrm{pM}$ target microRNA, according to Scheme 1 . The $R_{\mathrm{et}}$ increased after deposition of each layer of the recognition film. This increase indicated that the film became more insulating and its electrical double-layer properties remained as those of an ideal capacitor. The $R_{\text {et }}$ of the polymer modified sensor (after 30 potential cycles of polymer deposition) was $1.6 \pm 0.1 \mathrm{k} \Omega$. Then, the $R_{\text {et }}$ increased to $3.1 \pm 0.2 \mathrm{k} \Omega$ after streptavidin binding to the biotinylated interface because of partial hydrophobic insulation of the electrode surface. Subsequent surface immobilization of polyanionic DNA-CPs further increased the $R_{\mathrm{et}}(9.0 \pm 0.6 \mathrm{k} \Omega)$, as a result of electrostatic repulsion of the redox probe, thus increasing the energy barrier for the interfacial electron transfer. Finally, a further increase of the $R_{\text {et }}$ was observed by exposing the biosensor to $1 \mathrm{pM}$ solution of the target miR-221 (12 $\pm 1 \mathrm{k} \Omega)$. This $R_{\text {et }}$ consecutive increase was in accord with the higher negative charge accumulated on the genosensor surface, as a result of hybridization, thus enhancing electrostatic repulsion of the electroactive species present in solution.

In summary, the interfacial $R_{\text {et }}$ gradually increased in the course of building the surface assembly, thus confirming the interaction between the functional polymer and oligonucleotide $\mathrm{CP}$, as well as the hybridization of the $\mathrm{CP}$ with the target analyte.

The change of morphology and structure of the electrode surface after polymer deposition in the course of 30 potential cycles was monitored by FE-SEM imaging (Figure 3). Generally, the use of the In-lens detector enables more adequate representation of the examined surface and, moreover, the contrast of a SEM micrograph correlates with the difference in atomic numbers of the elements present in the sample. This advantage is clearly demonstrated in Figure $3 \mathrm{a}$ where the Auand carbon-rich zones are white and gray, respectively. The SEM micrographs show the presence of typical gold nanostructures for the bare gold WE (Figure 3a) while these nanostructures are hindered after electrochemical deposition of the polymer film on top of these nanostructures (Figure $3 b)$. The gold nanostructures are quite polydisperse with their dimensions ranging from the tenths of nanometer to the micrometer scale.

The presence of biotin molecules on the electrode surface was confirmed by FTIR spectroscopy measurements (Figure S2). The spectra for bare gold WEs (B), WEs treated with sulphuric acid (T), WEs treated with the aqueous solvent solution (S), and WEs coated with 
polymer films were examined. Moreover, spectra for the biotin and the monomer powder were recorded for comparison. Considering limiting cases, one can see that $\mathrm{B}, \mathrm{T}$, and $\mathrm{S}$ spectra reveal a very broad absorption centered at $\sim 1740 \mathrm{~cm}^{-1}$ while spectra for biotin and the monomer show a broad band at $\sim 1700 \mathrm{~cm}^{-1}$. All these bands can be ascribed to the $\mathrm{C}=\mathrm{O}$ stretching modes characteristic of different carbonyl functional groups present in the five samples examined. As soon as the polymer film was deposited on the bare WE, a band at $1720 \mathrm{~cm}^{-1}$ appeared. This spectral change confirms immobilization of the biotin moiety in the deposited film and is the result of the convolution of the carbonyl absorptions found in the limiting cases.

Additional peaks in the $3200-3400 \mathrm{~cm}^{-1}$ region can be attributed to the amine $(\mathrm{N}-\mathrm{H})$ groups present in the biotin moiety. These bands appear as quite resolved peaks in the biotin spectrum, whereas they appear as a broad band in both the monomer and polymer spectra, and are absent in the spectra of the $\mathrm{S}, \mathrm{T}$, and B samples.

\subsection{Analytical performance of the genosensor}

In order to demonstrate analytical performance of the genosensor, a calibration experiment was designed (Figure 4). The $\left(R-R_{0}\right) / R_{0}=\Delta R_{\mathrm{et}} / R_{0}$ ratio was used as the analytical signal, where $R$ represents the resistance recorded in presence of the target, and $R_{0}$ the resistance recorded for the PB (blank), respectively. In the concentration range of 1 to $100 \mathrm{pM}$, the genosensor response exhibited linear dependence on concentration of the target $\left(r^{2}=0.99\right)$. Reproducibility was evaluated by using at least three independently prepared genosensors; a relative standard deviation of $15 \%$ (expressed as the mean of all concentration tested) was obtained.

The LOD was determined according to the $3 \times S_{b}$ criterion, where $S_{b}$ was estimated as the standard deviation of the blank measurements and fitting to the respective equation of the linear portion of the plot. An LOD of 0.7 pM was estimated. Table S2 compares analytical performance of electrochemical genosensors for miRNA determination described in literature. The LOD value determined in the present work is in line with the values that have been already reported (Tran et al., 2014a), (Li et al., 2014), (Erdem and Congur, 2014), (Voccia et al., 2016), (Bettazzi et al., 2013), or even lower (Lusi et al., 2009). Nevertheless, lower LOD values were reported for approaches involving multiple reagents (Ren et al., 2013), (Xia et al., 2013), (Li et al., 2015). Advantageously, the present LOD value was reached without using any amplification and, moreover, did not require any preliminary target labeling.

Selectivity of the genosensor was evaluated by analyzing two different miRNA sequences, i.e., miR-16 and miR-21, often present in the same tumors where miR-221 is misregulated (Chatterjee et al., 2015), (Mobarra et al., 2015), (Jansson and Lund, 2012), (Iorio et al., 2005), (Di 
Leva et al., 2010), (M Garofalo et al., 2008). In particular, miR-16 is deregulated in B-cell chronic lymphocytic leukemia, lung cancers, and breast cancers (Rivas et al., 2012), (Pekarsky and Croce, 2015). The miR-21 sequence is misregulated in breast tumors and, in particular, it is progressively up-regulated from normal breasts to cancers with high tumor stage (Iorio et al., 2005). However, both these sequences markedly differ from the miR-221 sequence. They can, therefore, be regarded as a fully non-complementary sequence that can be present in the same sample (i.e., the RNA tot extracted from the cells) where miR-221 is also present.

As depicted in Figure $\mathrm{S} 3$, the $\Delta R_{\mathrm{et}} / R_{0}$ ratio (taking the $\Delta R_{\mathrm{et}} / R_{0}$ ratio for miR-221 as $100 \%$ ) decreased to a negligible value when miR-16 and miR-21 were examined even at high concentrations.

Moreover, the selectivity was evaluated by analyzing miR-222 sequence. The miR-221 and miR-222 are two highly homologous miRNAs (Bettazzi et al., 2013) encoded in tandem on the X chromosome (in other words, they are of the same miRNA family). They are involved in the development and progression of different types of epithelial cancers. The miR-222 hybridization efficiency was $\sim 30 \%$ for all the concentrations tested (Figure S3) assuming 100\% complementary hybridization efficiency for the miR-221 target.

However, as already reported for other miRNAs (Torrente-Rodríguez et al., 2015), (Bartosik et al., 2014), our preliminary studies showed that discrimination with respect to miR-222 could be improved by hybridizing miR-221 at melting temperature of the miR-222/CP hybrid. With this approach, the signal measured herein was decreased from $30 \%$ to $18 \%$ of that corresponding to miR-221 (Figure S4).

Moreover, stability of the devised genosensor was evaluated. The $\Delta R_{\mathrm{et}} / R_{0}$ ratio $(0.5 \mathrm{nM}$ target concentration) was determined in the same day of genosensor preparation and compared with those after storage for 20 days at $4{ }^{\circ} \mathrm{C}$ in PB. Then, a response of $\sim 90 \%$ of the initial value (Figure S5) was obtained. This value is in accordance with data recently reported in literature for other genosensor formats (Benvidi et al., 2015), (Benvidi and Jahanbani, 2016), (Benvidi et al., 2016).

\subsection{Determination of miRNA-221 in $\mathbf{R N A}_{\text {tot }}$ extracted from cancer cells}

Concentration levels of miR-221 are altered in several malignancies including lung and breast cancers. Therefore, $\mathrm{RNA}_{\text {tot }}$ extracted from the human lung- and breast-cancer cells was analyzed by the herein devised genosensor. Three different cell lines, i.e., Calu1, H460, and T47D have been tested.

The Calu1 and H460 cells are well-characterized NSCLC cell lines and miR-221 is overexpressed in Calu1, as compared with H460 (Garofalo et al., 2009), (Michela Garofalo et al., 
2008). In contrast, T47D is a human breast cancer cell line that was modified (transfected) in different ways, resulting in cells capable of either overexpressing or downexpressing miR-221 in comparison to their controls.

In fact, four different cell types were obtained including i) miR-221 transfected samples (T47D-miR-221), capable of overexpressing miR-221; ii) scrambled-sequence transfected T47D cells (T47D-Scr), used as the control of sample i; iii) anti-miR-221 transfected samples (T47D antimiR), capable of downexpressing miR-221; and iv) anti-scrambled-sequence transfected T47D cells (T47D-antiScr), used as the control of sample iii.

Results obtained with the use of our genosensor show an over-expression of miR-221 in Calu1 with respect to H460 (Figure 5). This behavior was further confirmed by qRT-PCR (Figure S6) remaining in agreement with that reported in literature (M Garofalo et al., 2008). Multiple analyses of the RNA extracted from the cell samples were performed.

In Figure 6, the results for different samples of the T47D cell line are shown. As expected, the signal obtained for the T47D-antimiR samples was lower than that for the T47D-antiScr (a control sample, i.e., the cell transfected with the anti-scrambled sequence). In particular, the expression level of $15 \%$ for the T47D-antimiR sample was observed assuming the $100 \%$ miR-221 expression level for the T47D-antiScr sample. On the contrary, a pronounced signal was obtained for the T47D-miR-221 samples compared to that for its control (T47D-Scr). Moreover, the over-expression of miR221, observed in the T47D-miR-221 samples with respect to the control sample (T47D-Scr), was confirmed by the qRT-PCR analysis (Figure S7).

The above results show that the developed assay can potentially be employed as analytical method for screening purposes of discriminating tumoral from non-tumoral tissues.

\section{Conclusions}

A label-free electrochemical genosensor using screen-printed gold electrodes was devised and fabricated. The use of inexpensive electrodes and the label-free determination protocol made the present genosensing approach particularly attractive for constructing a POCT device. A relatively short analysis time of $\sim 1.20 \mathrm{~h}$ and simplicity of the determination procedure are two additional advantages of the proposed assay. This label-free procedure relies on the increase of the electron transfer resistance, $R_{\mathrm{et}}$, incurred by target hybridization, thus leading to target recognition. Apparently, surface immobilization of the DNA probe plays a crucial role in devising the genosensor. This is because it strongly determines the bio-recognition capabilities of the genosensor and, hence, its sensitivity. The use of a conducting biotinylated polymer film was herein investigated as an enhanced immobilization strategy for the DNA capture probe. Potentiodynamic 
polymer deposition is a straightforward, low cost, and repeatable way of modification of the sensor surface. The electropolymerization was thoroughly characterized, confirming both polymer film formation and the presence of the biotin moiety. The calibration plot, constructed for the target miRNA sequence, showed the linear dynamic concentration range of 1 to $100 \mathrm{pM}$ and the LOD of $0.7 \mathrm{pM}$. The results for $\mathrm{RNA}_{\text {tot }}$ extracted from different cell lines indicated that our method is suitable to discriminate between cancer and non-cancer samples.

\section{Acknowledgements}

Funding Palchetti - This work was supported by Ministero dell'Istruzione, dell'Università e della Ricerca (MIUR) in the framework of PRIN 2012 (Grant No.20128ZZS2H) and byEnte Cassa di Risparmio di Firenze project ID PED 8780 2014.0757A2202.0734.

EF acknowledges partial financial support from CSGI. Dr. G. Ferraro is kindly acknowledged for the help with FTIR experiments.

Funding Condorelli - This work was partially supported by funds from Associazione Italiana Ricerca sul Cancro, AIRC (Grant No.10620) to G.C., MERIT (RBNE08E8CZ_002) to G.C., Fondazione Berlucchi to G.C.

Funding Sosnowska - This work was partially supported by the Foundation for Polish Science (Grant No. MPD/2009/1/styp15 to M.S.).

Funding Kutner - This work was partially supported by the Polish National Science Centre (Grant No. 2014/15/B/NZ/01011 to W.K.

Funding D'Souza - This work was supported by the US-National Science Foundation (Grant No. 1401188 to F.D.). 


\section{References}

Bartosik, M., Hrstka, R., Palecek, E., Vojtesek, B., 2014. Magnetic bead-based hybridization assay for electrochemical detection of microRNA. Anal. Chim. Acta 813, 35-40. doi:http://dx.doi.org/10.1016/j.aca.2014.01.023

Baydemir, G., Bettazzi, F., Palchetti, I., Voccia, D., 2016. Strategies for The development of an electrochemical bioassay for tnf-Alpha detection by using a non-immunoglobulin bioreceptor. Talanta 151, 141-147. doi:http://dx.doi.org/10.1016/j.talanta.2016.01.021

Benvidi, A., Dehghani Firouzabadi, A., Dehghan Tezerjani, M., Moshtaghiun, S.M., MazloumArdakani, M., Ansarin, A., 2015. A highly sensitive and selective electrochemical DNA biosensor to diagnose breast cancer. J. Electroanal. Chem. 750, 57-64. doi:http://dx.doi.org/10.1016/j.jelechem.2015.05.002

Benvidi, A., Jahanbani, S., 2016. Self-assembled monolayer of SH-DNA strand on a magnetic bar carbon paste electrode modified with Fe3O4@Ag nanoparticles for detection of breast cancer mutation. J. Electroanal. Chem. 768, 47-54. doi:http://dx.doi.org/10.1016/j.jelechem.2016.02.038

Benvidi, A., Tezerjani, M.D., Jahanbani, S., Mazloum Ardakani, M., Moshtaghioun, S.M., 2016. Comparison of impedimetric detection of DNA hybridization on the various biosensors based on modified glassy carbon electrodes with PANHS and nanomaterials of RGO and MWCNTs. Talanta 147, 621-627. doi:http://dx.doi.org/10.1016/j.talanta.2015.10.043

Bettazzi, F., Hamid-Asl, E., Esposito, C., Quintavalle, C., Formisano, N., Laschi, S., Catuogno, S., Iaboni, M., Marrazza, G., Mascini, M., Cerchia, L., De Franciscis, V., Condorelli, G., Palchetti, I., 2013. Electrochemical detection of miRNA-222 by use of a magnetic bead-based bioassay. Anal. Bioanal. Chem. 405, 1025-1034. doi:10.1007/s00216-012-6476-7

Campuzano, S., Pedrero, M., Pingarrón, J.M., 2016. Viral protein-based bioanalytical tools for small RNA biosensing. TrAC Trends Anal. Chem. 79, 335-343. doi:http://dx.doi.org/10.1016/j.trac.2015.09.012

Campuzano, S., Pedrero, M., Pingarrón, J.M., 2014. Electrochemical genosensors for the detection of cancer-related miRNAs. Anal. Bioanal. Chem. 406, 27-33. doi:10.1007/s00216-013-7459-z

Chatterjee, A., Chattopadhyay, D., Chakrabarti, G., 2015. miR-16 targets Bcl-2 in paclitaxelresistant lung cancer cells and overexpression of miR-16 along with miR-17 causes unprecedented sensitivity by simultaneously modulating autophagy and apoptosis. Cell. Signal. 27, 189-203. doi:http://dx.doi.org/10.1016/j.cellsig.2014.11.023

Cortez, M.A., Bueso-Ramos, C., Ferdin, J., Lopez-Berestein, G., Sood, A.K., Calin, G.A., 2011. MicroRNAs in body fluids - the mix of hormones and biomarkers. Nat. Rev. Clin. Oncol. 8, 467-477. doi:10.1038/nrclinonc.2011.76

Cosnier, S., Holzinger, M., 2011. Electrosynthesized polymers for biosensing. Chem. Soc. Rev. 40, 2146-2156. doi:10.1039/C0CS00090F

Deng, H., Shen, W., Ren, Y., Gao, Z., 2014. A highly sensitive microRNA biosensor based on hybridized microRNA-guided deposition of polyaniline. Biosens. Bioelectron. 60, 195-200. doi:http://dx.doi.org/10.1016/j.bios.2014.04.023

Di Leva, G., Gasparini, P., Piovan, C., Ngankeu, A., Garofalo, M., Taccioli, C., Iorio, M. V, Li, M., Volinia, S., Alder, H., Nakamura, T., Nuovo, G., Liu, Y., Nephew, K.P., Croce, C.M., 2010. MicroRNA Cluster 221-222 and Estrogen Receptor $\alpha$ Interactions in Breast Cancer. JNCI J. Natl. Cancer Inst. 102, 706-721. doi:10.1093/jnci/djq102

Erdem, A., Congur, G., 2014. Label-free voltammetric detection of MicroRNAs at multi-channel screen printed array of electrodes comparison to graphite sensors. Talanta 118, 7-13. doi:http://dx.doi.org/10.1016/j.talanta.2013.09.041

Gao, Z., Deng, H., Shen, W., Ren, Y., 2013. A Label-Free Biosensor for Electrochemical Detection 
of Femtomolar MicroRNAs. Anal. Chem. 85, 1624-1630. doi:10.1021/ac302883c

Garofalo, M., Condorelli, G., Croce, C.M., 2008. MicroRNAs in diseases and drug response. Curr. Opin. Pharmacol. 8, 661-667. doi:10.1016/j.coph.2008.06.005

Garofalo, M., Condorelli, G.L., Croce, C.M., Condorelli, G., 2009. MicroRNAs as regulators of death receptors signaling. Cell Death Differ 17, 200-208.

Garofalo, M., Quintavalle, C., Di Leva, G., Zanca, C., Romano, G., Taccioli, C., Liu, C.G., Croce, C.M., Condorelli, G., 2008. MicroRNA signatures of TRAIL resistance in human non-small cell lung cancer. Oncogene 27, 3845-3855.

Graybill, R.M., Bailey, R.C., 2016. Emerging Biosensing Approaches for microRNA Analysis. Anal. Chem. 88, 431-450. doi:10.1021/acs.analchem.5b04679

Heinze, J., Rasche, A., Pagels, M., Geschke, B., 2007. On the Origin of the So-Called Nucleation Loop during Electropolymerization of Conducting Polymers. J. Phys. Chem. B 111, 989-997. doi:10.1021/jp066413p

Huynh, T.-P., Bikram K.C., C., Lisowski, W., D’Souza, F., Kutner, W., 2013a. Molecularly imprinted polymer of bis(2,2'-bithienyl)methanes for selective determination of adrenaline. Bioelectrochemistry 93, 37-45. doi:http://dx.doi.org/10.1016/j.bioelechem.2012.07.003

Huynh, T.-P., Pietrzyk-Le, A., Bikram K.C., C., Noworyta, K.R., Sobczak, J.W., Sharma, P.S., D'Souza, F., Kutner, W., 2013b. Electrochemically synthesized molecularly imprinted polymer of thiophene derivatives for flow-injection analysis determination of adenosine-5'triphosphate (ATP). Biosens. Bioelectron. 41, 634-641. doi:http://dx.doi.org/10.1016/j.bios.2012.09.038

Huynh, T.-P., Sharma, P.S., Sosnowska, M., D’Souza, F., Kutner, W., 2015. Functionalized polythiophenes: Recognition materials for chemosensors and biosensors of superior sensitivity, selectivity, and detectability. Prog. Polym. Sci. 47, 1-25. doi:http://dx.doi.org/10.1016/j.progpolymsci.2015.04.009

Iorio, M. V, Ferracin, M., Liu, C.-G., Veronese, A., Spizzo, R., Sabbioni, S., Magri, E., Pedriali, M., Fabbri, M., Campiglio, M., Ménard, S., Palazzo, J.P., Rosenberg, A., Musiani, P., Volinia, S., Nenci, I., Calin, G.A., Querzoli, P., Negrini, M., Croce, C.M., 2005. MicroRNA Gene Expression Deregulation in Human Breast Cancer. Cancer Res. 65 , 7065-7070.

Jansson, M.D., Lund, A.H., 2012. MicroRNA and cancer. Mol. Oncol. 6, 590-610. doi:10.1016/j.molonc.2012.09.006

Kakhki, S., Barsan, M.M., Shams, E., Brett, C.M.A., 2012. Development and characterization of poly(3,4-ethylenedioxythiophene)-coated poly(methylene blue)-modified carbon electrodes. Synth. Met. 161, 2718-2726. doi:http://dx.doi.org/10.1016/j.synthmet.2011.10.007

Kilic, T., Kaplan, M., Demiroglu, S., Erdem, A., Ozsoz, M., 2016. Label-Free Electrochemical Detection of MicroRNA-122 in Real Samples by Graphene Modified Disposable Electrodes. J. Electrochem. Soc. 163 , B227-B233.

Labib, M., Berezovski, M. V, 2015. Electrochemical sensing of microRNAs: Avenues and paradigms. Biosens. Bioelectron. 68, 83-94. doi:http://dx.doi.org/10.1016/j.bios.2014.12.026

Li, F., Peng, J., Wang, J., Tang, H., Tan, L., Xie, Q., Yao, S., 2014. Carbon nanotube-based labelfree electrochemical biosensor for sensitive detection of miRNA-24. Biosens. Bioelectron. 54, 158-164. doi:http://dx.doi.org/10.1016/j.bios.2013.10.061

Li, F., Peng, J., Zheng, Q., Guo, X., Tang, H., Yao, S., 2015. Carbon Nanotube-Polyamidoamine Dendrimer Hybrid-Modified Electrodes for Highly Sensitive Electrochemical Detection of MicroRNA24. Anal. Chem. 87, 4806-4813. doi:10.1021/acs.analchem.5b00093

Lucarelli, F., Marrazza, G., Mascini, M., 2005. Enzyme-based impedimetric detection of PCR products using oligonucleotide-modified screen-printed gold electrodes. Biosens. Bioelectron. 20, 2001-2009. doi:http://dx.doi.org/10.1016/j.bios.2004.08.025

Lusi, E.A., Passamano, M., Guarascio, P., Scarpa, A., Schiavo, L., 2009. Innovative Electrochemical Approach for an Early Detection of microRNAs. Anal. Chem. 81, 2819-2822. doi:10.1021/ac8026788 
Mobarra, N., Shafiee, A., Rad, S.M.A.H., Tasharrofi, N., Soufi-zomorod, M., Hafizi, M., Movahed, M., kouhkan, F., Soleimani, M., 2015. Overexpression of microRNA-16 declines cellular growth, proliferation and induces apoptosis in human breast cancer cells. Vitr. Cell. Dev. Biol. - Anim. 51, 604-611. doi:10.1007/s11626-015-9872-4

Palchetti, I., 2014. Affinity biosensors for tumor-marker analysis. Bioanalysis 6, 3417-3435. doi:10.4155/bio.14.247

Pekarsky, Y., Croce, C.M., 2015. Role of miR-15/16 in CLL. Cell Death Differ. 22, 6-11. doi:10.1038/cdd.2014.87

Pietrzyk, A., Suriyanarayanan, S., Kutner, W., Chitta, R., D’Souza, F., 2009. Selective Histamine Piezoelectric Chemosensor Using a Recognition Film of the Molecularly Imprinted Polymer of Bis(bithiophene) Derivatives. Anal. Chem. 81, 2633-2643. doi:10.1021/ac8025652

Ren, Y., Deng, H., Shen, W., Gao, Z., 2013. A Highly Sensitive and Selective Electrochemical Biosensor for Direct Detection of MicroRNAs in Serum. Anal. Chem. 85, 4784-4789. doi:10.1021/ac400583e

Rivas, M.A., Venturutti, L., Huang, Y.-W., Schillaci, R., Huang, T.H.-M., Elizalde, P. V, 2012. Downregulation of the tumor-suppressor miR-16 via progestin-mediated oncogenic signaling contributes to breast cancer development. Breast Cancer Res. 14, 1-21. doi:10.1186/bcr3187

Sosnowska, M., Pieta, P., Sharma, P.S., Chitta, R., KC, C.B., Bandi, V., D’Souza, F., Kutner, W., 2013. Piezomicrogravimetric and Impedimetric Oligonucleotide Biosensors Using Conducting Polymers of Biotinylated Bis(2,2'-bithien-5-yl)methane as Recognition Units. Anal. Chem. 85, 7454-7461. doi:10.1021/ac401404d

Spires, J.B., Peng, H., Williams, D., Travas-Sejdic, J., 2011. An improved terthiophene conducting polymer for DNA-sensing. Electrochim. Acta 58, 134-141. doi:http://dx.doi.org/10.1016/j.electacta.2011.09.016

Teo, A.K.L., Lim, C. Le, Gao, Z., 2014. The development of electrochemical assays for microRNAs. Electrochim. Acta 126, 19-30. doi:http://dx.doi.org/10.1016/j.electacta.2013.06.113

Torrente-Rodríguez, R.M., Campuzano, S., López-Hernández, E., Montiel, V.R.-V., Barderas, R., Granados, R., Sánchez-Puelles, J.M., Pingarrón, J.M., 2015. Simultaneous detection of two breast cancer-related miRNAs in tumor tissues using p19-based disposable amperometric magnetobiosensing platforms. Biosens. Bioelectron. 66, 385-391. doi:http://dx.doi.org/10.1016/j.bios.2014.11.047

Tran, H. V, Piro, B., Reisberg, S., Anquetin, G., Duc, H.T., Pham, M.C., 2014a. An innovative strategy for direct electrochemical detection of microRNA biomarkers. Anal. Bioanal. Chem. 406, 1241-1244. doi:10.1007/s00216-013-7292-4

Tran, H. V, Piro, B., Reisberg, S., Huy Nguyen, L., Dung Nguyen, T., Duc, H.T., Pham, M.C., 2014b. An electrochemical ELISA-like immunosensor for miRNAs detection based on screenprinted gold electrodes modified with reduced graphene oxide and carbon nanotubes. Biosens. Bioelectron. 62, 25-30. doi:http://dx.doi.org/10.1016/j.bios.2014.06.014

Tran, H. V, Piro, B., Reisberg, S., Tran, L.D., Duc, H.T., Pham, M.C., 2013. Label-free and reagentless electrochemical detection of microRNAs using a conducting polymer nanostructured by carbon nanotubes: Application to prostate cancer biomarker miR-141. Biosens. Bioelectron. 49, 164-169. doi:http://dx.doi.org/10.1016/j.bios.2013.05.007

Voccia, D., Bettazzi, F., Baydemir, G., Palchetti, I., 2015. Alkaline-Phosphatase-Based Nanostructure Assemblies for Electrochemical Detection of microRNAs. J. Nanosci. Nanotechnol. 15, 3378-3384. doi:doi:10.1166/jnn.2015.10201

Voccia, D., Bettazzi, F., Fratini, E., Berti, D., Palchetti, I., 2016. Improving impedimetric nucleic acid detection by using enzyme-decorated liposomes and nanostructured screen-printed electrodes. Anal. Bioanal. Chem. 1-11. doi:10.1007/s00216-016-9593-x

Xia, N., Zhang, L., Wang, G., Feng, Q., Liu, L., 2013. Label-free and sensitive strategy for microRNAs detection based on the formation of boronate ester bonds and the dual- 
amplification of gold nanoparticles. Biosens. Bioelectron. 47, 461-466.

doi:http://dx.doi.org/10.1016/j.bios.2013.03.074 


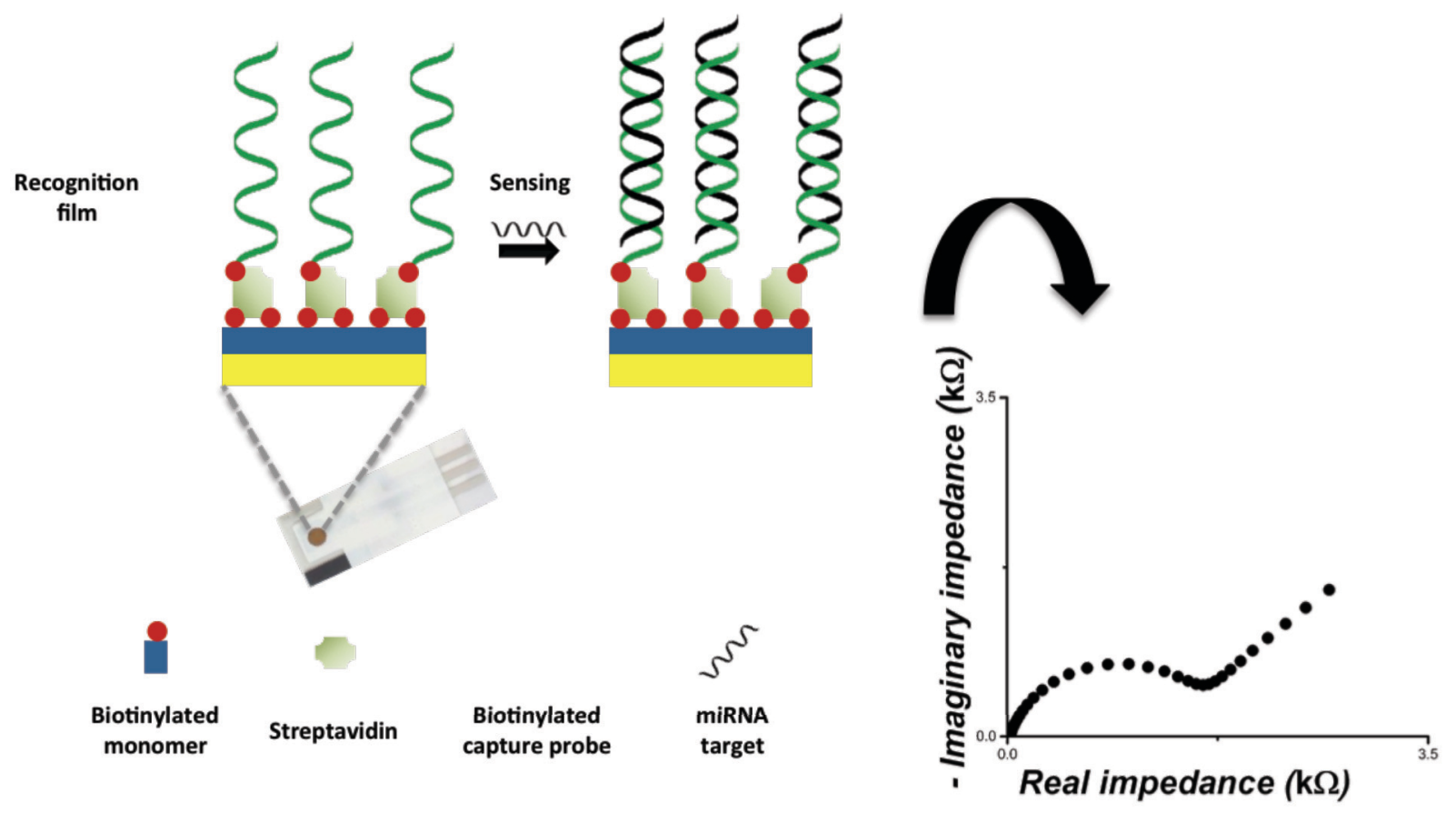

Graphical Abstract 


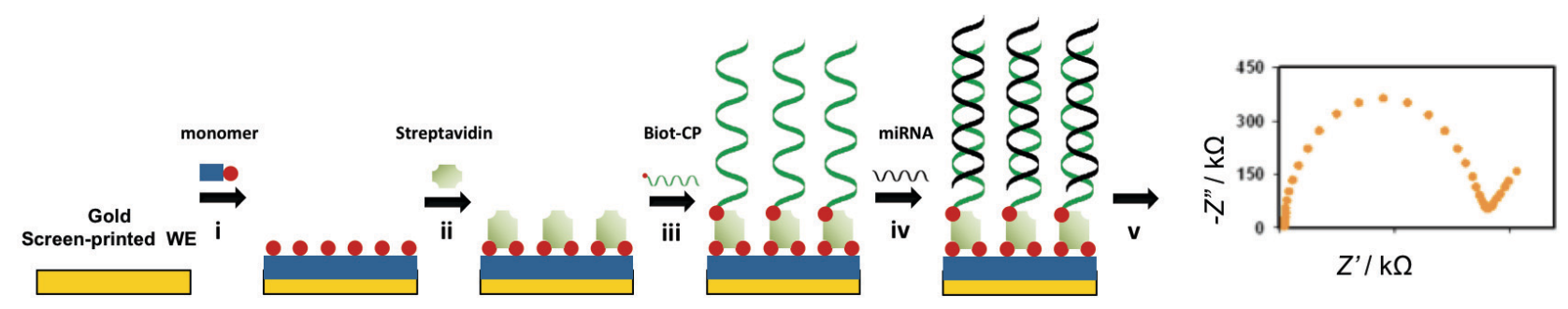

Scheme 1. Illustration of the consecutive steps of label-free assay scheme. (i) The pretreated gold surface was exposed to a monomer aqueous solution for electropolymerization. (ii) Next, the biotinylated modified surface was exposed to streptavidin solution in PB, and then (iii) immersed in a PB solution of the biotinylated capture probe (Biot-CP). (iv) Finally, this recognition film was exposed to the target $\mathrm{PB}$ solution and the EIS measurement was performed in presence of $\mathrm{Fe}(\mathrm{CN})_{6}{ }^{3-}$ 14-. (v) The resulting electron transfer resistance values, were taken as the analytical signals. 


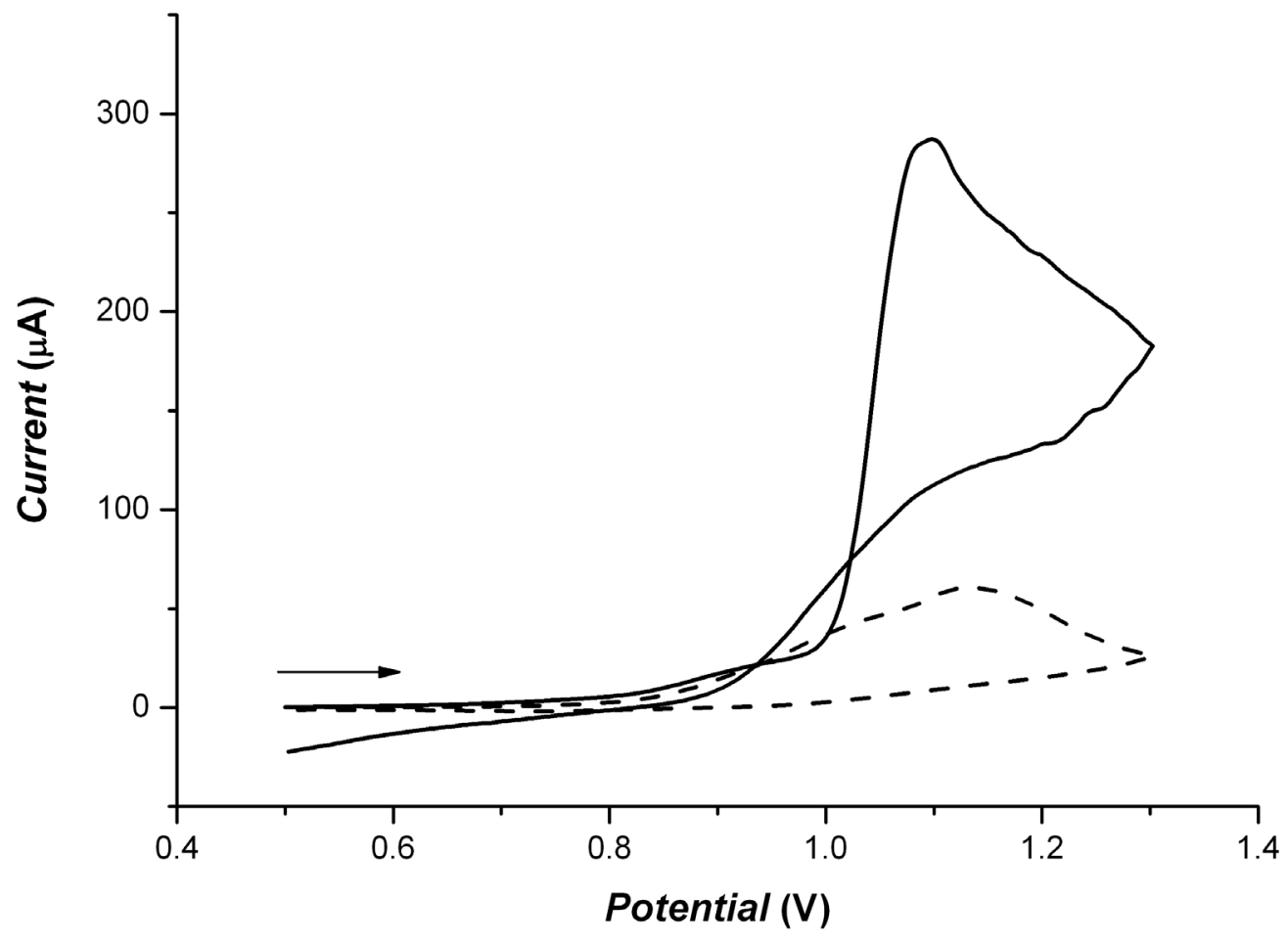

Figure 1. Cyclic voltammogram for the $0.1 \mathrm{mM}$ monomer in $10 \mathrm{mM}$ (TBA)Br ethanol : acetonitrile : water, $1: 1: 10(v / v / v)$ solution (solid curve) recorded at the gold screen-printed electrode for the first potential cycle in the +0.50 to $+1.30 \mathrm{~V}$ potential range. The cyclic voltammetry of the (TBA)Br supporting electrolyte solution (dash curve), for the first potential cycle, was also reported. The potential was scanned with a scan rate of $50 \mathrm{mV} / \mathrm{s}$. 


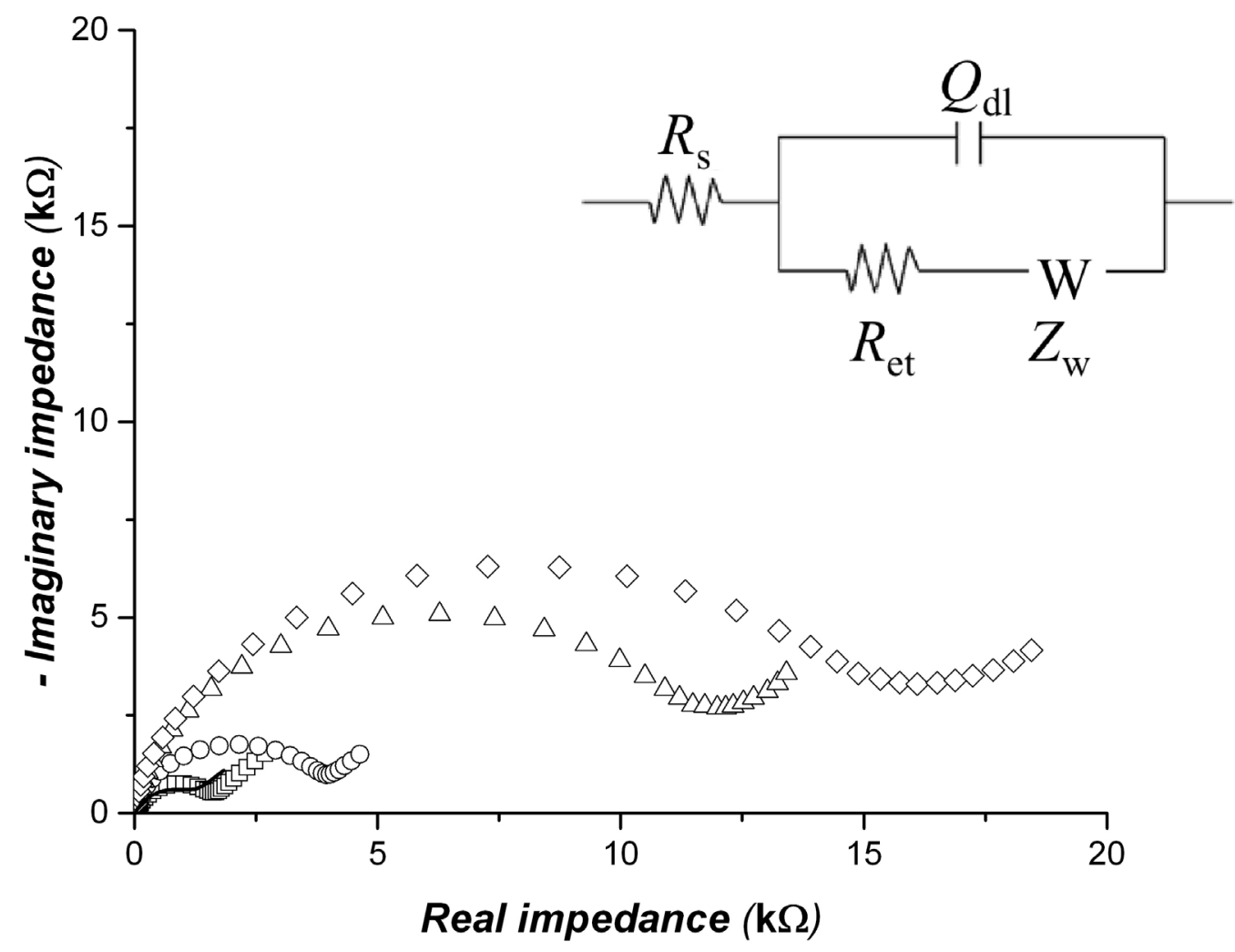

Figure 2. The effect of the electrode surface modification on the impedimetric signals. The impedance spectra (Nyquist plots) are shown after $(\square)$ electropolymerization, $(\bigcirc)$ streptavidin deposition, $(\triangle)$ capture probe binding, and $(\diamond) 1 \mathrm{pM}$ miRNA hybridization. EIS parameters are reported in Experimental. $1 \mathrm{mM} \mathrm{Fe}(\mathrm{CN})_{6}{ }^{3-/ 4-}$ couple was used as the redox probe. The solid curve corresponds to the impedance spectrum of the bare (non-modified) gold screen-printed electrode. 

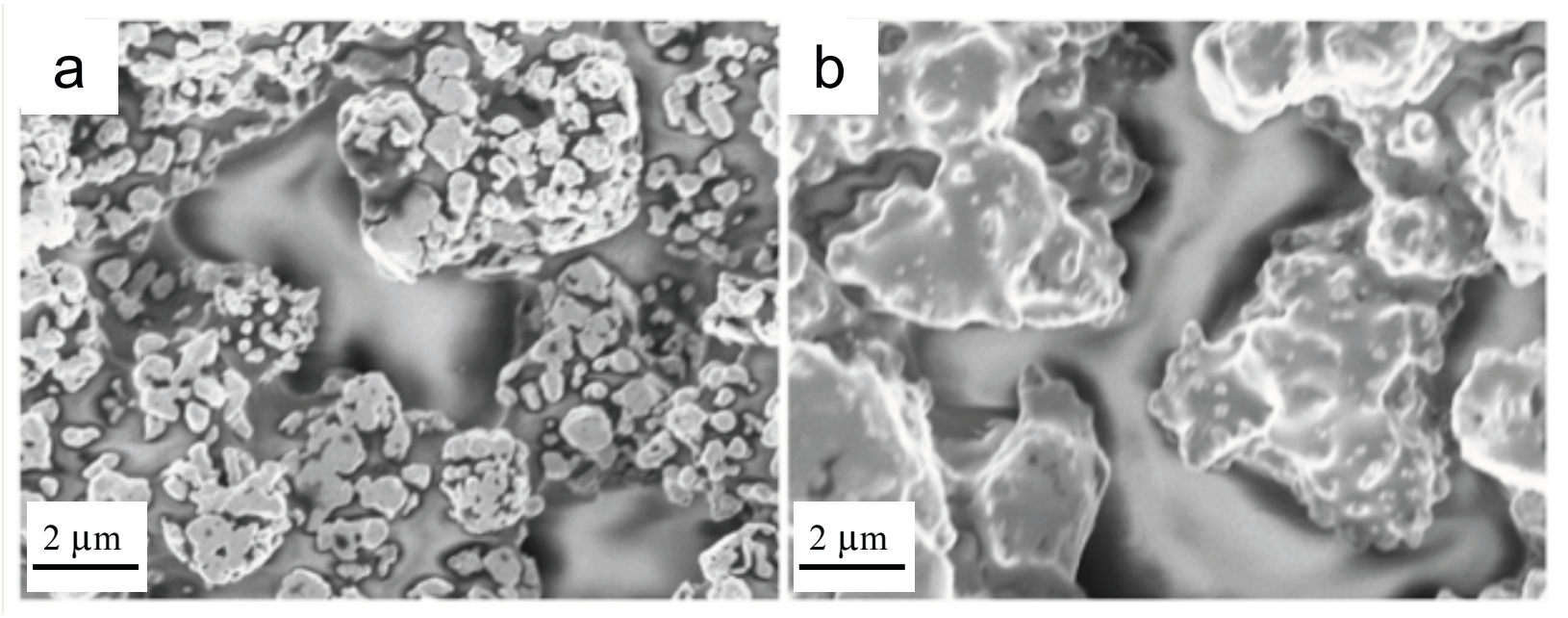

Figure 3. FE-SEM images of non-metallizzed samples of (a) a bare gold screen-printed electrode showing typical roughness and structures of polycrystalline gold and (b) the polymer film coated gold screen-printed electrode. All samples were prepared as described in Experimental. 


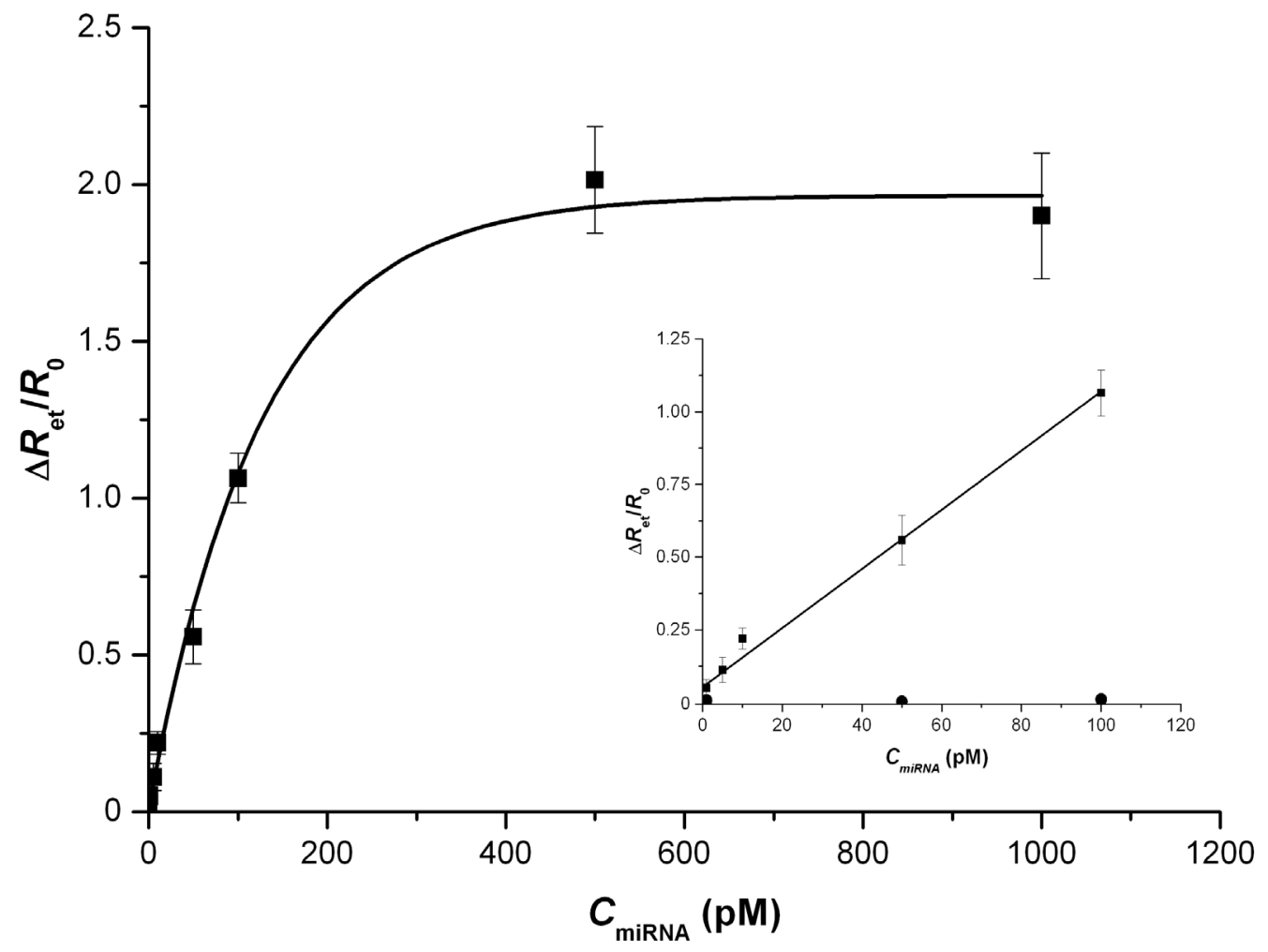

Figure 4. (घ) The calibration plot for miR-221. Inset shows the linear segment of the plot from 1 to $100 \mathrm{pM}, \mathrm{r}^{2}=0.99$. (•) The signal for a non-complementary sequence (miR-16) at 1, 50 and $100 \mathrm{pM}$ concentration is also shown in the Inset. Each data point represents the mean of at least three measurements (using independently prepared genosensors) and the error bars represent the corresponding standard deviations. 
a)

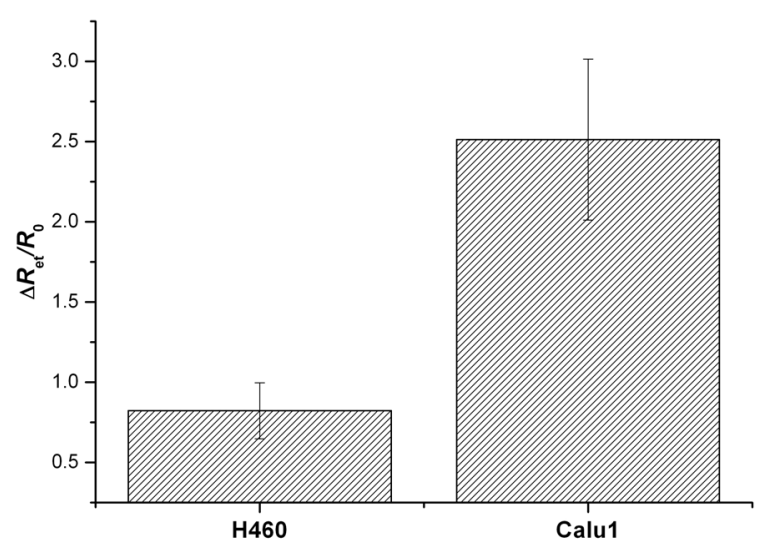

b)

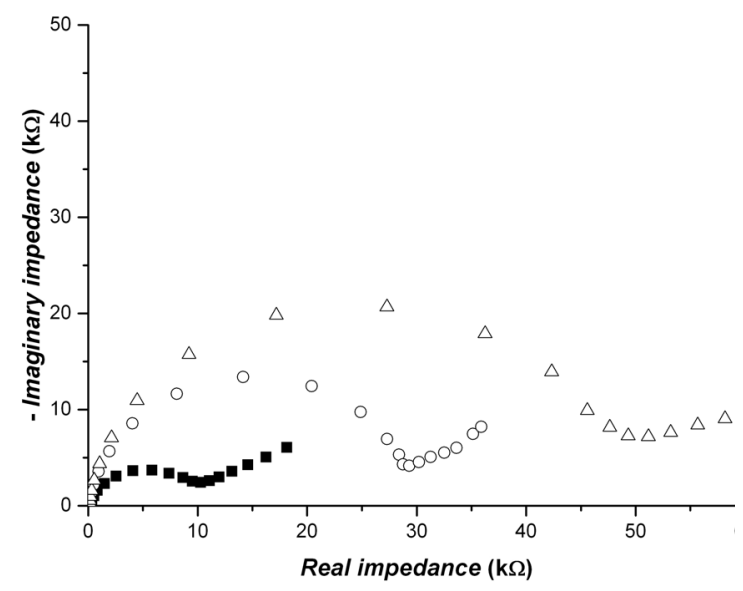

Figure 5. Analysis of NSCLC cell samples. The RNA tot was extracted from the Calul and H460 cell lines. After extraction, $\mathrm{RNA}_{\text {tot }}$ was immobilized on the $\mathrm{CP}$ modified sensor and tested using the $1 \mathrm{mM} \mathrm{Fe}(\mathrm{CN})_{6}{ }^{3-/ 4-}$ solution (equimolar mixture) redox probe in $0.1 \mathrm{M} \mathrm{PBS}(\mathrm{pH}=7.4)$. (a) The $\Delta R_{\mathrm{et}} / R_{0}$ values for $100 \mathrm{ng} / \mu \mathrm{L} \mathrm{RNA}_{\text {tot }}$ from $\mathrm{H} 460$ and Calu1. (b) The corresponding Nyquist plots for the $(\mathrm{O}) \mathrm{H} 460,(\triangle)$ Calul and ( $\boldsymbol{\square})$ PB blank exposed genosensors. Error bars represent standard deviations of at least three repetitions. 
a)

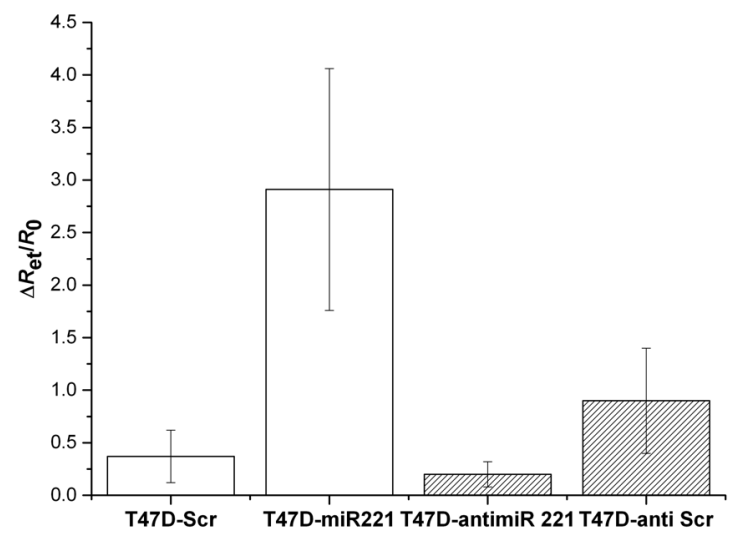

b)

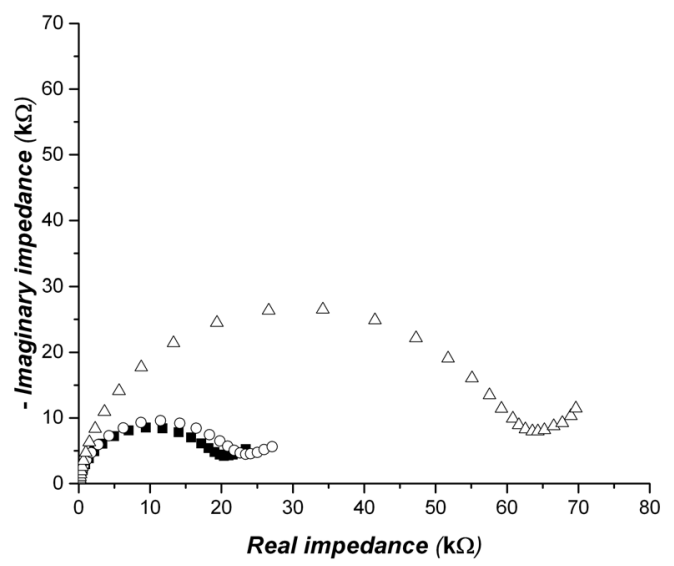

Figure 6. Analysis of breast cancer cell samples. The RNA tot was extracted from the T47D breast cancer cell lines. After extraction, $\mathrm{RNA}_{\text {tot }}$ was immobilized on the $\mathrm{CP}$ modified sensor and tested using the $1 \mathrm{mM} \mathrm{Fe}(\mathrm{CN})_{6}{ }^{3-/ 4-}$ solution (equimolar mixture) in $0.1 \mathrm{M} \mathrm{PBS}(\mathrm{pH}=7.4)$. (a) The $\Delta R_{\mathrm{et}} / R_{0}$ values for $10 \mathrm{ng} / \mu \mathrm{L} \mathrm{RNA}_{\text {tot }}$ (white histogram bars) from the T47D-miR221 transfected cell samples and the scrambled transfected cell samples (T47D-Scr) as well as $300 \mathrm{ng} / \mu \mathrm{L} \mathrm{RNA}$ tot (patterned histogram bars) from the T47D-antimiR transfected samples and anti-scrambled transfected (T47DantiScr). (b) The corresponding Nyquist plots of (O) T47D-Scr and $(\triangle)$ T47D-miR221 exposed sensors with results compared to the sensor exposed to (ש) PB. Error bars represent standard deviations of three repetitions. 